\title{
PELATIHAN DAN PEDAMPINGAN PELAKSANAAN BASIC LIFE SUPPORT DI KALANGAN REMAJA
}

\author{
Triyana Sari ${ }^{1}$, Raynold Kaisar Gusti ${ }^{2}$, Jihan Putri Allyssa ${ }^{3}$ \\ ${ }^{1}$ Bagian Biologi , Fakultas Kedokteran, Universitas Tarumanagara Jakarta \\ Email:triyanas@fk.untar.ac.id \\ ${ }^{2}$ Mahasiswa Fakultas Kedokteran Universitas Tarumanagara Jakarta \\ Email:raykaisar14@gmail.com \\ ${ }^{3}$ Mahasiswa Fakultas Kedokteran Universitas Tarumanagara Jakarta \\ Email:jihanputriallyssa@gmail.com
}

\begin{abstract}
Basic Life Support (BLS) is an action to maintain the patient's life with the first step of rapid recognition to provide emergency ventilation and circulatory support in respiratory or cardiac cases. The quality of basic life support provided for cardiac arrest outside the hospital is often less than optimal and knowledge of basic life support skills in the general public, especially students, is not good. Based on the problems above, we conducted activities related to introduction accompanied by education in the form of basic life support training. The purpose of service activities related to basic life support is to introduce basic life support and improve student skills related to basic life support. The basic life support training service activity on Sunday, September 26, 2021, starting at 08.00-13.00 WIB, was attended by 76 participants consisting of 60 women and 16 men, aged 17-22 years old. Participants who participated in basic life support training as much as $72 \%$ had never attended training and $28 \%$ had attended training. The average pretest score on basic life support training was 58.77 and the posttest average score was 68.42. So based on the results of the pretest and posttest that have been carried out by the basic life support training participants, there was an increase of $16.41 \%$, with this the service activities that we carried out had increased the knowledge of participants who took part in basic life support training.
\end{abstract}

Keywords: Basic Life Support, skill, training

\begin{abstract}
ABSTRAK
Bantuan Hidup Dasar atau Basic Life Support/BLS adalah suatu tindakan untuk mempertahankan hidup pasien dengan langkah pertama pengenalan cepat untuk memberikan ventilasi darurat dan dukungan sirkulasi dalam kasus pernapasan atau jantung. Kualitas bantuan hidup dasar yang diberikan pada serangan jantung di luar rumah sakit seringkali kurang optimal serta pengetahuan keterampilan bantuan hidup dasar di masyarakat umum khususnya mahasiwa kurang baik. Berdasarkan permasalahan di atas kami melakukan kegiatan PKM terkait pengenalan disertai edukasi berupa pelatihan bantuan hidup dasar. Tujuan kegiatan pengabdian terkait bantuan hidup dasar adalah memperkenalkan tentang bantuan hidup dasar serta meningkatkan keterampilan mahasiswa terkait bantuan hidup dasar. Kegiatan pengabdian pelatihan bantuan hidup dasar pada hari Minggu tanggal 26 September 2021, dimulai dari pukul 08.00-13.00 WIB, diikuti 76 peserta terdiri dari 60 perempuan dan 16 laki-laki, berusia 17-22 tahun dapat berlangsung dengan baik. Peserta yang mengikuti pelatihan bantuan hidup dasar sebanyak $72 \%$ belum pernah mengikuti pelatihan dan $28 \%$ sudah pernah mengikuti pelatihan. Nilai rata-rata pretest tentang pelatihan bantuan hidup dasar sebesar 58,77 dan Nilai rata-rata posttest-nya adalah 68,42. Maka berdasarkan hasil pretest dan posttest yang telah dikerjakan peserta pelatihan bantuan hidup dasar terjadi peningkatan sebesar $16,41 \%$, dengan ini kegiatan pengabdian yang kami lakukan telah menambah pengetahuan peserta yang mengikuti pelatihan bantuan hidup dasar.
\end{abstract}

Kata kunci:Bantuan Hidup Dasar, keterampilan, pelatihan

\section{PENDAHULUAN}

Bantuan hidup dasar adalah suatu tindakan kegawatdaruratan untuk pasien yang terdiri dari beberapa teknik seperti resusitasi jantung dan paru, tata laksana syok, dan pertolongan pertama dengan tujuan untuk mempertahankan hidup pasien sampai kedatangan fasilitas medis atau orang pergi ke rumah sakit. Bantuan hidup dasar merupakan langkah pertama pengenalan cepat untuk memberikan ventilasi darurat dan dukungan sirkulasi dalam kasus pernapasan atau jantung. Keterampilan BLS terdiri atas pernapasan dan kompresi dada untuk menormalkan 
sirkulasi darah ke otak dan organ vital. Studi sebelumnya melaporkan serangan jantung, aktivasi sistem layanan medis darurat, resusitasi jantung paru dini dan defibrilasi dapat membuat perbedaan waktu antara hidup dan mati (Katerina B et.al, 2019)

Implementasi bantuan hidup dasar berupa ventilasi buatan dan kompresi dada dilakukan pada orang yang memiliki gangguan pernapasan dan/atau serangan jantung dengan keadaan perangkat medis tidak dapat diakses. Bantuan hidup dasar dilakukan pada kasus henti jantung mendadak dan henti napas. Serangan jantung mendadak penyebab kematian jutaan orang setiap tahun di seluruh dunia. Di Eropa, 350.000-700.000 orang per tahun mengalami serangan jantung mendadak di luar rumah sakit (Perkins, 2015)

Cara untuk meningkatkan tingkat kelangsungan hidup pada kasus henti jantung adalah melakukan kehidupan dasar yang dini dan defibrilasi awal (Gates S, Quinn, 2015; HasselqvistAx I, et.al.,2015). Otak manusia selama serangan jantung mendadak dapat menahan hipoksia sekitar 4-5 menit dan kerusakan otak mulai terjadi pada 5 menit selanjutnya karena hipoksia, dan kerusakan otak permanen terjadi setelah menit kesepuluh (Lee, K, 2012; Shemie SD, Gardiner D, 2018).

Pelatihan Bantuan Hidup Dasar yang sesuai aturan harus segera diterapkan, sehingga masyarakat harus diberikan pelatihan tentang bantuan hidup dasar. Upaya tindakan Bantuan Hidup Dasar yang tepat dilakukan sampai tim penyelamat darurat tiba, maka ribuan orang per tahun dapat diselamatkan. Serangan jantung di luar rumah sakit merupakan penyebab utama kematian dan morbiditas. Faktor kunci yang meningkatkan kelangsungan hidup adalah tindakan bantuan hidup dasar berkualitas baik (Nishiyama C, et al, 2014). Standar bantuan hidup dasar bertujuan untuk meningkatkan prognosis serangan jantung di luar rumah sakit yang merupakan faktor kritis serta mencegah komplikasi dari kondisi kritis (Sasson, et al, 2010).

\section{Permasalahan Mitra}

Kualitas bantuan hidup dasar yang pada masyarakat di luar rumah sakit khususnya mahasiswa kurang optimal. Masih sedikitnya minat dari mahasiswa mengetahui tentang bantuan hidup dasar dan pengetahuan BHD sangat penting dimiliki mahasiswa agar dapat membantu jika menghadapi kasus yang memerlukan tindakan bantuan hidup dasar pada korban kecelakaan atau yang sedang dalam perjalanan yang mengalami henti nafas atau henti jantung dengan tepat. Berdasarkan pemasalahan yang terjadi tim pengabdian melakukan pelatihan kesehatan dengan materi bantuan hidup dasar.

\section{METODE PELAKSANAAN PKM}

Metode pelaksanaan PKM adalah pelatihan interaktif dengan pemutaran video serta pemberian materi, diskusi, demonstrasi, simulasi BLS pada pasien yang mengalami henti jantung atau nafas, pendampingan secara daring, serta dilakukan evaluasi dalam pelaksanaan bantuan hidup dasar yang telah dilakukan. Materi yang disampaikan terdiri konsep basic life support atau bantuan hidup dasar serta langkah - langkah pelaksanaan bantuan hidup dasar. Kegiatan edukasi terkait bantuan hidup dasar dilakukan hari Minggu tanggal 26 September 2021. Kegiatan edukasi dilakukan secara daring. Pada edukasi pengetahuan Bantuan Hidup Dasar dilakukan pretest dan postest dengan tujuan menilai tingkat pengetahuan serta tingkat wawasan pengetahuan sebelum dan sesudah pelatihan Bantuan Hidup Dasar. Pada kegiatan ini, pretest dan postest dilakukan dengan mengisi Google form yang disediakan oleh tim pengusul. Tautan untuk gform diberikan kepada para peserta sebelum pretes dan postes dilakukan. Materi pertanyaan pretest dan postest berisikan pertanyaan sebanyak 9 soal yang sama terkait dengan materi pelatihan yang diberikan oleh narasumber. 


\section{HASIL DAN PEMBAHASAN}

Kegiatan pelatihan Bantuan Hidup Dasar dapat dilaksanakan ke peserta pada hari Minggu tanggal 26 September 2021, dimulai dari pukul 08.00-13.00 WIB. Kegiatan pelatihan Bantuan Hidup Dasar. Jumlah peserta yang mengikuti pelatihan Bantuan Hidup dasar sebanyak oleh 76 peserta. Tim pengabdian membuka acara pelatihan dengan memberi salam serta mengucapkan salam agar suasana pelatihan tidak kaku serta menari. Kegiatan pelatihan tahun ini dengan menggunakan aplikasi zoom meeting tidak dapat tatap muka karena masih dalam kondisi pandemi dan PPKM.

Tim Pengabdian memulai dengan meminta para peserta pelatihan mengisi pretest yang disebarkan via chat Room. Metode pelaksanaanya terhadap peserta menggunakan penyuluhan mencakup konsep bantuan hidup dasar yang terdiri dari pengertian, tujuan, manfaat, prinsip dalam melakukan bantuan hidup dasar, indikasi pelaksanaan bantuan hidup dasar, persiapan penolong dalam pemberian bantuan hidup dasar, langkah - langkah pelaksanaan bantuan hidup dasar, hal yang perlu diperhatikan pada saat melakukan bantuan hidup dasar, komponen yang harus ada pada penolong saat melakukan bantuan hidup dasar, komplikasi apabila salah dalam melakukan bantuan hidup dasar, demonstrasi, simulasi tindakan bantuan hidup dasar dengan pasien yang mengalami henti jantung atau nafas, pendampingan secara daring, serta evaluasi dalam pelaksanaan bantuan hidup dasar yang telah dilakukan. Peserta kegiatan pelatihan sangat tertarik dengan materi yang disampaikan sehingga mereka langsung bertanya apabila ada materi kegiatan kurang di pahami. Setelah dilakukan penyampaian materi maka tim pengabdian mengingatkan untuk mengisi posttest.

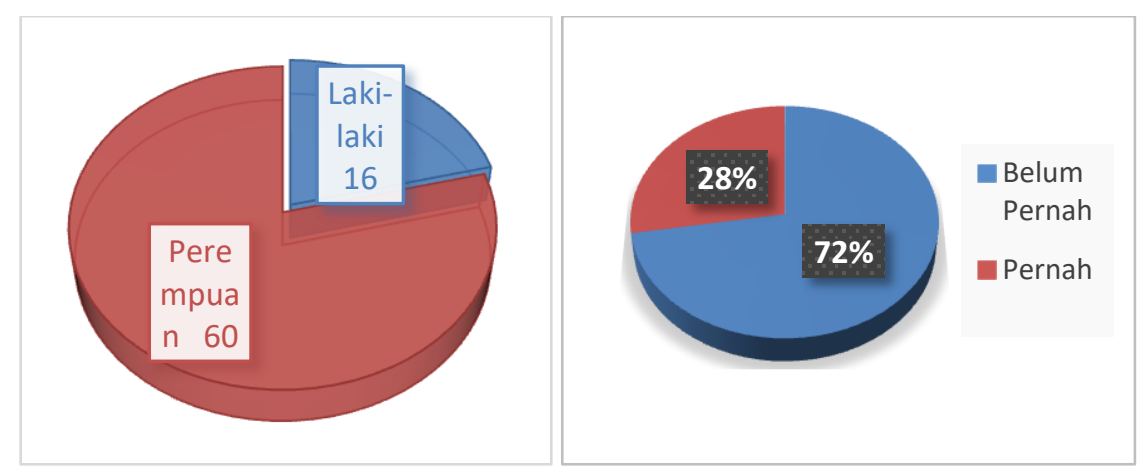

\section{Gambar 1. Diagram Hasil Kegiatan}

Kegiatan pengabdian bantuan hidup dasar yang diikuti 76 peserta terdiri dari 60 perempuan dan 16 laki-laki, berusia 17-22 tahun, pada pertanyaan" apakah sudah pernah mengikuti pelatihan bantuan hidup dasar " didapatkan hasil $72 \%$ belum pernah mengikuti pelatihan dan $28 \%$ sudah pernah mengikuti pelatihan. Nilai rata-rata pretest tentang pelatihan bantuan hidup dasar sebesar 58,77 dan Nilai rata-rata posttestnya adalah 68,42. Maka berdasarkan hasil pretest dan posttest yang telah dikerjakan peserta pelatihan BHD terjadi peningkatan sebesar $16,41 \%$, dengan ini kegiatan pengabdian yang kami lakukan telah menambah pengetahuan peserta yang mengikuti pelatihan bantuan hidup dasar. Edukasi yang dibentuk dalam pelatihan serta penyuluhan dengan materi bantuan hidup dasar berfokus untuk menambah wawasan keterampilan peserta sejalan meningkatnya pengetahuan bantuan hidup dasar. Tujuan kegiatan pengabdian pelatihan Bantuan Hidup Dasar adalah memperkenalkan tentang prinsip utama bantuan hidup dasar serta meningkatkan keterampilan mahasiswa terkait bantuan hidup dasar. Target jangka pendek dari pelatihan ini adalah bertambahnya pengetahuan bantuan hidup dasar serta minat peserta untuk mengembangkan keterampilan pada bantuan hidup dasar. Manfaat yang diperoleh dari kegiatan 
pelatihan bantuan hidup dasar adalah peserta yang telah mengikuti pelatihan bertambah wawasannya terkait bantuan hidup dasar sehingga dapat melakukan tindakan bantuan hidup dasar dengan tepat. Respon yang diberikan peserta saat tim pengabdian meminta umpan balik bahwa materi pelatihan bermanfaat dan peserta puas dengan kegiatan pelatihan serta mau mengikuti lagi apabila ada kegiatan pelatihan bantuan hidup dasar.

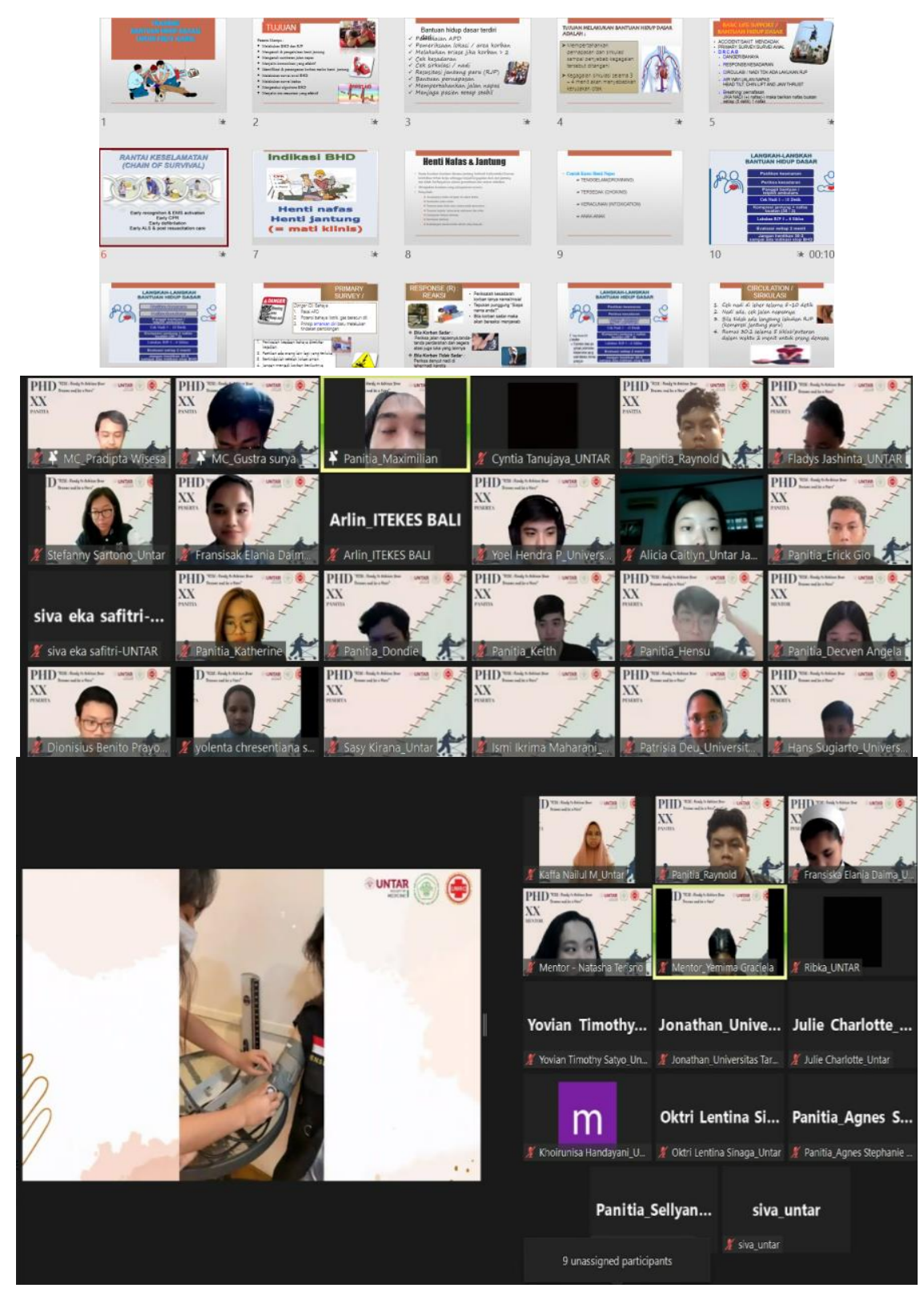

Gambar 2. Materi dan peserta kegiatan.

\section{KESIMPULAN DAN SARAN}

Kegiatan pengabdian pelatihan bantuan hidup dasar pada hari Minggu tanggal 26 September 2021, dimulai dari pukul 08.00-13.00 WIB, diikuti 76 peserta terdiri dari 60 perempuan dan 16 laki-laki, berusia 17-22 tahun dapat berlangsung dengan baik. Peserta yang mengikuti pelatihan bantuan hidup dasar sebanyak $72 \%$ belum pernah mengikuti pelatihan dan $28 \%$ sudah pernah mengikuti pelatihan. Nilai rata-rata pretest tentang pelatihan bantuan hidup dasar sebesar 58,77 dan Nilai rata-rata posttest-nya adalah 68,42. Maka berdasarkan hasil pretest dan posttest yang 
telah dikerjakan peserta pelatihan bantuan hidup dasar terjadi peningkatan sebesar 16,41\%, dengan ini kegiatan pengabdian yang kami lakukan telah menambah pengetahuan peserta yang mengikuti pelatihan bantuan hidup dasar. Tingginya minat untuk pelatihan bantuan hidup dasar yang ditargetkan pada dewasa muda hendak terus dipertahankan serta dilakukan 6-12 bulan untuk mempertahankan mengingat serta memperbarui lagi pengetahuan serta keterampilan bantuan hidup dasar.

\section{Ucapan Terima Kasih (Acknowledgement)}

Ucapan terima kasih penulis sampaikan Lembaga Penelitian dan Pengabdian kepada Masyarakat UNTAR atas pendanaan dalam kegiatan ini. Terima kasih juga disampaikan kepada seluruh peserta yang telah mengikuti kegiatan bakti kesehatan ini, sehingga kegiatan dapat terlaksana dengan baik dan lancar. Terima kasih juga kepada Panitia SENAPENMAS yang sudah memberikan kesempatan untuk berpatisipasi pada kegiatan SENAPENMAS 2021.

\section{REFERENSI}

Gates S, Quinn T, Deakin CD, Blair L, Couper K, Perkins GD, et al. (2015). Mechanical chest compression for out of hospital cardiac arrest: Systematic review and meta-analysis. Resuscitation. 94: p. 91-7. https://www.resuscitationjournal.com/article/S03009572(15)00310-X/fulltext\#secsect0040

Hasselqvist-Ax I, Riva G, Herlitz J, Rosenqvist M, Hollenberg J, Nordberg P,et al. (2015).Early cardiopulmonary resuscitation in out-of-hospital cardiac arrest.. N Engl J Med,. 372(24): p. 2307-15. DOI: 10.1056/NEJMoa1405796

Katerina B , Andrej Š,Monika Š , Gordana A , Marija A, Aleksandra P, Taša L, Jasminka P. (2019). Cardiopulmonary Resuscitation Performed by Trained Providers and Shorter Time to Emergency Medical Team Arrival Increased Patients Survival Rates in Istra County, Croatia : A Retrospective Study." : 325-32DOI:10.3325/cmj.2019.60.325

Lee, K, (2012).Cardiopulmonary resuscitation: new concept. Tuberc Respir Dis.. 72(5): p. 401-8. doi: $\underline{10.4046 / \operatorname{trd} .2012 .72 .5 .401}$

Nishiyama C, Brown SP, May S, et al. (2014). Apples to apples or apples to oranges? International variation in reporting of process and outcome of care for out-ofhospital cardiac arrest.

Resuscitation;85:1599-609. https://doi.org/10.1016/j.resuscitation.2014.06.031

Perkins GD, Handley AJ, Koster RW, Castren M, Smyth MA, Olasveegen T, et al. (2015) European Resuscitation Council Guidelines for Resuscitation 2015: Section 2. Adult basic life support and automated external defibrillation. Resuscitation, 2015. 95: p. 81-99. http://dx.doi.org/10.1016/j.resuscitation.2015.07.015

Sasson C, Rogers MA, Dahl J, Kellermann AL. (2010). Predictors of Survival From Out-ofHospital Cardiac Arrest. Circ Cardiovasc Qual Outcomes. Jan;3(1):63-81. doi: 10.1161/CIRCOUTCOMES.109.889576https://pubmed.ncbi.nlm.nih.gov/20123673/

Shemie SD, Gardiner D.(2018).Circulatory Arrest, Brain Arrest and Death Determination. Front Cardiovasc Med, 5: p.15.doi: 10.3389/fcvm.2018.00015 
Seminar Nasional Hasil Penelitian dan Pengabdian Kepada Masyarakat 2021

Pengembangan Ekonomi Bangsa Melalui Inovasi Digital Hasil Penelitian dan

Pengabdian Kepada Masyarakat

Jakarta, 21 Oktober 2021

(halaman kosong) 